Chirurgia (2019) 114: 7-11

No. 1, January - February

Copyright $@$ Celsius

http://dx.doi.org/10.21614/chirurgia.114.1.7

\title{
History, Perspectives and Actual Trends in the Field of Herniology
}

\section{Daniel Ion}

The University of Medicine and Pharmacy "Carol Davila", Bucharest, Romania

The Emergency University Hospital of Bucharest, Romania

Corresponding author:

Daniel Ion, MD

The University of Medicine and

Pharmacy "Carol Davila", Bucharest

The Emergency University Hospital

of Bucharest, Romania

E-mail: dr.daniel.ion@gmail.com
Herniology is one of the oldest surgical fields, and its history can basically be confused with the history of surgery in general. Its development followed the advances in anatomy, asepsia and antisepsia, and more recently, those in the field of minimally invasive technologies and synthetic materials. Until the modern age, surgery for hernias involved only the treatment of primary hernia complications, because, after the laparotomy had become a common procedure, the problem of solving incisional hernias was added; the latter is a reality that still occurs in about $10 \%$ of all laparatomies (1).

If we should mark some milestones in the evolution of surgical repair and reconstruction of the abdominal wall affected by a primary or incisional hernia, we should select from the entire labyrinth of surgical searches in this field only those concepts, gestures and techniques that were eventually validated by practice and retained as useful up to the present day.

- 1716 - Dimitrie Cantemir, voivode of Moldavia and member of the Academy of Sciences of Berlin, in the manuscript "Incrementa et decrementa Aulae Othomaniae" ("The History of the Growth and Decay of the Ottoman Empire") describes, for the first time, the transabdominal approach in the repair of hernias, performed at the Ottoman court by Albanian surgeons of time (2).

- 1871 - H. O. Marcy, the first promoter of asepsia in America, published the procedure called "simple closure of the deep inguinal opening", or the narrowing of the deep hole with a few insoluble threads crossed in the plane of the transversal fascia after the high dissection of the herniary sac (3). 
- 1884 - Eduardo Bassini begins to practice his own procedure based on the opening of the inguinal canal with the section and reconstruction of the posterior wall in the plane of the transversal fascia, making a triple layer (4).

- 1887 - Bassini communicates the first study called "The radical cure of inguinal hernia" at the Italian Society of Surgery for a total of 42 surgeries in 38 patients (5).

- 1889 - Bassini's book, illustrated by Caterina, entitled "The New Method for the Radical Cure of the Inguinal Hernia" comes out. The book includes a series of 262 operated inguinal hernia patients, followed for 4 years, with only 4 missing cases and a recurrence rate of only $2.7 \%$ (6).

- 1892 - Wolfler describes the relaxation incision in the anterior blade of the abdominal muscle as an adjunct in herniorrhaphy (7).

- 1892 - Jusepe Ruggi resolves femoral hernias by suturing the inguinal ligament to the Cooper ligament (8).

- 1901 - The overlapping, described by Mayo, becomes, at the time, the most common form of autoplasty practiced in the case of umbilical and white line hernias (9). This technique was based on what Ernest Juvara had already accomplished in 1900, namely an overlap of musculo-aponevrotic plans, called the "frock-coat" plasty (10).

- 1939 - Chester McVay proves that the transversal fascia is inferior to the Cooper ligament and not to the inguinal ligament. It restores the posterior wall by suturing the upper lip of the inguinal canal (conjunctive tendon) to the pectinate ligament (11).

- 1939-Tanner popularized the relaxation incision in the anterior blade of the right abdominal muscle, described by Wolfler in $1892(12,13)$.

- 1940 - Eduard Shouldice develops Bassini's concept of making the most effective tissue repair, still valid today, by reconstructing the posterior wall of the inguinal duct in a quadruple layer (two double surjet) with a metal wire under local anesthesia (14).

- 1956 - Henri Fruchaud elaborates the concept of a "miopectineal hole" delimited above the aponeurotic arc of the abdominal transversal muscle, inferiorly to the upper branch of the pubicum, medially to the lateral edge of the rectus abdominis and laterally to the psoas iliac muscle (15).

- 1958 -Francis Usher conceives and uses "Marlex", a polyethylene polymer to replace the posterior wall of the inguinal canal by placing the prosthesis in the preperitoneal space, in the anterior way (16).

- 1975 - Rives and Stoppa describe a prosthetic reinforcement of the visceral sac GPRVS (Giant Prosthetic Reinforcement of the Visceral Sac) (17).

- 1984 - Lichetenstein L. places a polypropylene prosthesis in front of the retrofunicular transversal fascia with a lateral slit through which the spermatic funicle passes. The closure of the slit, laterally to the funicular, recalibrates the deep inguinal opening (18).

- 1990 - Toy describes the intraperitoneal procedure - IPOM (intraperitoneal on lay mesh) in which the deficient myopectinous aperture is covered with an EPTFE (expanded polytetrafluoroethylene) prosthesis (19).

- 1990 - Ramirez et al. performs, for the first time, the anterior separation of components demonstrating that the external oblique muscle can be separated from the internal oblique muscle at a relatively avascular plane, allowing the white line to be restored in the large incisional hernias (20).

- 1991 - Arregui describes the transabdominal properitoneal process - TAPP - openly. By removing the peritoneal flap, which covers the miopectinous hole, he placed a polypropylene mesh next to it. Finally, the prosthesis is covered by the initial dissected peritoneal flap (21).

- 1991 - Dulucq - the total extraperitoneal 
process - TEP, openly placing a prosthesis in front of the hole of the miopectinate, getting access through the sheath of the right abdominal muscle by dissecting it under the navel, from which, through the perforation of the posterior blade) (22) .

- 1993 - LeBlanc and Booth report the first laparoscopic repair of an incisional hernia using expanded polytetrafluoroethylene (23).

- 1993 - McKernon and Laws described for the first time the total extraperitoneal laparoscopic approach - TEP (24).

- 1996 - Bittner R. et al and Leibl B. et al. describe the transabdominal preperitoneal laparoscopic approach (TAPP) (25).

In the organizational plan, the concerns in this field materialized in the founding of GREPA (Groupe de Recherche et d'Etudes de la Paroi Abdominale) in 1979 by Gilbert, Obney, Lichtenstein, Wantz, Pallier, Stoppa, Campanelli, Chevrel, Flamant, Negrro, Kreuzer, and Schumpelick. The success of GREPA led to its transformation into the European Hernia Society in 1998, and the launch of Hernia - The World Journal of Hernia and Abdominal Wall Surgery, which regularly publishes guides to good practice in the field (26).

So, after Bassini's bing-bang at the end of the $19^{\text {th }}$ century, the $20^{\text {th }}$ century witnessed two new revolutions in the field: synthetic meshes and minimally invasive, laparo-endoscopic techniques.

Perhaps illustrative for the change in perspective of hernia surgery are the current scales of assessment of postoperative outcomes, which have changed the center of gravity from relapse, on the elements that make up the quality of postoperative life - chronic pain, mobility, local sensitivity disorders, foreign body sensation a rapid resumption of physical activity $(27,28)$.

The superiority of prosthetic procedures is underlined by most studies, and the only tissue-suture technique rivaling with them is Schouldice, even though it remains the competence of specialized centers for selected patients. In addition, it is laborious and hard to reproduce. Literature abounds in studies and debates about the advantages and disadvantages of the two approaches - open or minimally invasive (29-31). If at the beginning of the prosthesis era there was a fervent search for the ideal mesh, the last decade selected a small number of base materials of which the most commonly used is polypropylene in various combinations and forms (32-34).

The hopes of biological tapes regarding biocompatibility and efficiency in the contaminated environment have only been confirmed to a small extent, so they have a low utilization rate, given their high costs $(35,36)$.

In the open approach, two gold-standard procedures were imposed: the Lichtenstein operation for the inguinal hernia, and RivesStoppa for the incisional hernias. In the laparo-endoscopic approach, the basic TAPP and TEP procedures remain the gold standard.

Open procedures are easy to reproduce, safe in terms of relapse, but objectionable in terms of functional and cosmetic results.

Laparo-endoscopic procedures are technology - dependent and require a relatively long learning curve, not always applicable to complicated cases. For example, for TEP, the learning curve ranges from 50 to 100 procedures, where the critical area is in the first 30 (37).

An example of the ongoing "tandem" evolution of open and laparoscopic, tissue and prosthetic procedures is the Ramirez process, originally conceived as an open tissue procedure meant to slide the abdominal musculoaponevrotic layers to cover large defects without resorting to replacement prostheses.

Subsequently, the posterior separation (between the internal oblique and the transversus) will be performed so that the "trans" versus abdominal relase" (TAR) can be reached today - the separation of the abdominal transverse from the underlying peritoneal-fascial plane. Starting from the principle stated by this author, this procedure was associated with prosthetic techniques, first open and then laparo-endoscopic. Thus, Rives-Stoppa procedures in which the previous separation, rear separation or TAR (38) can be associated in various combinations (open and / or laparoscopic) are carried out. 
Beyond the actual surgical techniques, the laparo-endoscopic approach has made remarkable contributions to the in vivo understanding of the anatomy, starting from the embryological origin of the musculoskeletal planes to the distribution of the nerve elements of each anatomical layer, reflected in improved functional results (39).

The approach of increasingly large and complex parieto-abdominal defects through the extensive use of prostheses has brought attention to postoperative intra-abdominal hypertension syndrome (40). At the same time, the pneumoperitoneum performed for laparoscopy allowed understanding of the pathophysiology of intra-abdominal hypertension in general, and in particular that caused by the abrupt reduction in the contents of a voluminous herniar sac in the abdomen. Thus, the idea of adapting the abdominal wall closure techniques to the intra-abdominal presumptive situation, either by augmentation or by parietal substitution (the separation of the components, respectively the substitution mesh), has been reached.

A possible decalogue in abdominal wall repair surgery should include:

1. The surgeon's understanding of the current status change in hernia surgery, from the peripheral and easy surgical field, to the rather specialized field, with standardized procedures, with high expectations of quality of life for patients.

2. The first step in the treatment of incisional hernias is the acquisition of the correct and proper closing techniques of the initial laparatomy - in other words, prevention.

3. Complete renouncement of historical hernia repair procedures by acquiring current techniques in a training center and making a periodic upgrade. In 1998 Wantz said: "Deficient Surgical Education is the most important obstacle to superior performance in non-specialized centers" (41).

4. Adaptation of current therapies to local conditions, but without rebate in terms of mandatory minimum quality standards.
5. Selection of cases and type of operation in relation to the lesion and biological background of the patient.

6. Avoiding excessive trust in technology. It becomes an advantage only in the hands of a surgeon who possesses the appropriate expertise.

7. The prosthesis, in various technical variants, has become the foundation stone in repairing the abdominal wall, but the prosthesis does not cover the surgeon's lack of expertise.

8. Referral of cases with difficult incisional hernias or recurrent hernias to dedicated, specialized centers.

9. Expanding the indication of primary prosthesis of laparatomy in patients at increased risk of incisional hernia or in other particular situations, e.g. colostomy.

10. Improvement of abdominal wall repair surgery results cannot be achieved without systematic follow-up, ultimately reflected in a national hernia registry.

\section{References}

1. Nachiappan S, Markar S, Karthikesalingam A, Ziprin P, Faiz 0. Prophylactic mesh placement in high-risk patients undergoing elective laparotomy: a systematic review. World J Surg. 2013; 37(8):1861-71. Erratum in: World J Surg. 2013;37(7):1747.

2. Nicolau AE. Demetrius Cantemir: the first account of transabodominal approach to repair groin hernia. Acta Chir Belg. 2009;109(4):565-9.

3. Marcy HO. The radical cure of hernia by the antiseptic use of carbolized catgut ligature. Trans AMA. 1878;29:295-305.

4. Bassini E. Sopra 100 casi de cura radical dell'ernia inguinale operata col metododell'autore. Arch. ed Atti Soc. Ital.Chir. 1888;5: 315-319.

5. Bassini E. Sulla cura radicale dell'ernia inguinale. Arch. Soc. Ital. Chir. 1887;4:380.

6. Bassini E. Nuovo metodo operativo per la cura radicale dell'ernia inguinale. Padova; 1889.

7. Wolfler A. Zur radikaloperation des Freien Leistenbruches in Beitr Chir (Festehr Guidmet Theodor Billroth). Stuttgart, Hoffman; 1892. p. 552-603.

8. Ruggi G. Nuovo metodo operativo per la cura radicale dell'erniacrurale. Bull Sci Med, Bologna; 1892.

9. Mayo W. VI. An Operation for the Radical Cure of Umbilical Hernia. Ann Surg. 1901;34(2):276-80.

10. Juvara E. La suture de la paroi abdominale par l'embrication des planes musculo-aponeurotiques. Arch Prov de Chir 9:538.

11. McVay CB. An anatomic error in current methods of inguinal herniorrhaphy. Ann Surg. 1941;113(6):1111-2.

12. Halsted WS. The radical cure of hernia. Johns Hopkins Hosp. Bull. 1889;1:12-13.

13. Tanner NC. A 'slide' operation for inguinal and femoral hernia. Br J Surg 1942;29:285-289.

14. Shouldice EE. The treatment of hernia. Ontario Med Rev. 1953;20: 670-84. 
15. Fruchaud H. Anatomie chirurgicale ds hernies de l'aine. Paris: G.Doin; 1956.

16. Usher FC. A new plastic prosthesis for repairing tissue defects of the chest and abdominal wall. Am J Surg. 1959;97(5):629-33.

17. Stoppa R, Petit J, Henry X. Unsutured Dacron prosthesis in groin hernias. Int Surg. 1975;60(8):411-2.

18. Lichtenstein IL. Herniorrhaphy. A personal experience with 6,321 cases. Am J Surg. 1987;153(6):553-9.

19. Toy FK, Smoot RT, Jr. Toy-Smooth laparoscopic hernioplasty. Surg Laparosc Endosc. 1991;1(3):151-5.

20. Ramirez OM, Ruas E, Dellon AL. 'Components separation' method for closure of abdominal-wall defects: an anatomic and clinical study. Plast Reconstr Surg. 1990;86(3):519-26.

21. Arregui ME, Davis CJ, Yucel O, Nagan RF. Laparoscopic mesh repair of inguinal hernia using a preperitoneal approach: a preliminary report. Surg Laparosc Endosc. 1992;2(1):53-8.

22. Dulucq JL. Traitement des hernies de l'aine par mise en place d'un patch prothétique sous-péritonéal en rétropéritonéoscopie. Cahiers de Chir 1991;79:15-6.

23. LeBlanc KA, Booth WV. Laparoscopic repair of incisional abdominal hernias using expanded polytetrafluoroethylene: preliminary findings. Surg Laparosc Endosc. 1993;3(1):39-41.

24. McKernan JB, Laws HL. Laparoscopic repair of inguinal hernias using a totally extraperitoneal prosthetic approach. Surg Endosc. 1993; 7(1):26-8.

25. Bittner R, Leibl B, Kraft K, Däubler P, Schwarz J. Laparoscopic hernioplasty (TAPP) - complications and recurrences in 900 operations. Zentralbl Chir. 1996;121(4):313-9. German.

26. http://www.europeanherniasociety.eu/ehs-grepa

27. Langbach 0, Bukholm I, Benth JŚ, Røkke 0 . Long-term quality of life and functionality after ventral hernia mesh repair. Surg Endosc. 2016;30(11):5023-33

28. Bansal VK, Krishna A, Manek P, Kumar S, Prajapati O, Subramaniam $\mathrm{R}$, et al. A prospective randomized comparison of testicular functions, sexual functions and quality of life following laparoscopic totally extra-peritoneal (TEP) and trans-abdominal pre-peritoneal (TAPP) inguinal hernia repairs. Surg Endosc. 2017;
31(3):1478-1486.

29. Eker HH, Hansson BM, Buunen M, Janssen IM, Pierik RE, Hop WC, et al. Laparoscopic vs. open incisional hernia repair: a randomized clinical trial. JAMA Surg. 2013;148(3):259-63.

30. Bowling K, El-Badawy S, Massri E, Rait J, Atkinson J, Leong S, et al. Laparoscopic and open inguinal hernia repair: Patient reported outcomes in the elderly from a single centre - A prospective cohort study. Ann Med Surg (Lond). 2017;22:12-15.

31. McCormack K, Scott NW, Go PM, Ross S, Grant AM; EU Hernia Trialists Collaboration. Laparoscopic techniques versus open techniques for inguinal hernia repair. Cochrane Database Syst Rev. 2003;(1):CD001785.

32. Brown CN, Finch JG. Which mesh for hernia repair?. Ann R Coll Surg Engl. 2010;92(4):272-8.

33. Elango S, Perumalsamy S, Ramachandran K, Vadodaria K. Mesh materials and hernia repair. Biomedicine (Taipei). 2017;7(3):16.

34. Bilsel Y, Abci I. The search for ideal hernia repair; mesh materials and types. Int J Surg. 2012;10(6):317-21.

35. FitzGerald JF, Kumar AS. Biologic versus synthetic, reinforcement: what are the pros and cons? Clin Colon Rectal Surg. 2014; 27(4):140-8.

36. Köckerling F, Alam NN, Narang SK, Daniels IR, Smart NJ. Biological meshes for inguinal hernia repair - review of the literature. Front Surg. 2015;2:48.

37. Bansal VK, Krishna A, Misra MC, Kumar S. Learning Curve in Laparoscopic Inguinal Hernia Repair: Experience at a Tertiary Care Centre. Indian J Surg. 2015;78(3):197-202.

38. Rosen MJ. Atlas of abdominal wall reconstruction. Elsevier Health Sciences; 2016.

39. Bendavid R. Abdominal wall hernias - principles and management. New York: Springer-Verlag; 2001.

40. Paduraru DN, Radu G, Andronic 0, Bolocan A, Ion D. Historical notes the history of the abdominal compartment syndrome, Journal of Surgical Sciences. 2017;4(1):pag. 46-51.

41. Wantz GE. Hernioplasty controversy. J Am Coll Surg. 1998;186(3): 372-3. 